\title{
Effect of electric pulse aging time on microstructure and properties of ZL114A alloy
}

\author{
K. Kang, D. Shi, G. Gao* \\ Department of Materials Science \& Engineering, Harbin University of Science \& Technology, Harbin \\ 150040, P. R. China
}

Received 12 March 2018, received in revised form 21 June 2018, accepted 29 June 2018

\begin{abstract}
A facile method for aging treatment of ZL114A alloy by using electric pulse, namely electric pulse aging treatment is explored in this study. When the pulse current, pulse frequency, and duty ratio are certain, aging time is changed. By analyzing the microstructure and properties, the aging treatment time of ZL114A alloy is significantly reduced by using electric pulse. The results show that the fine eutectics become coarse in the matrix with the increasing of aging time. Compared with the as-cast alloy, the hardness and conductivity values of ZL114A alloy increase significantly by using $4-7 \mathrm{~h}$ electric pulse aging treatment. The elongation of the alloy is tested to be $3.15 \%$ after aging treatment for $5 \mathrm{~h}$, which is higher than that of conventional heat treatment $(3 \%)$. Compared with the conventional heat treatment, aging time is reduced by $3 \mathrm{~h}$ so that energy is conserved. Based on the analysis of microstructure and mechanical properties obtained, the optimal electric pulse aging treatment parameters for ZL114A alloy were determined: pulse current $(8 \mathrm{~A})$, pulse frequency $(700 \mathrm{~Hz})$, duty cycle $( \pm 0.5)$, aging temperature $\left(160^{\circ} \mathrm{C}\right)$, and the aging time $(5 \mathrm{~h})$.
\end{abstract}

K e y words: electric pulse, aging treatment, ZL114A alloy, microstructure, properties

\section{Introduction}

In the non-ferrous metals, the application of aluminum and aluminum alloy is widely in the structural material. ZL114A alloy has excellent casting properties, good mechanical properties, corrosion resistance and welding performance, which is widely used in aerospace, transportation and other fields [1]. With the improvement of the alloy materials performance requirements, the general properties of ZL114A alloy are also putting forward higher requirements. Due to the existence of some defects in the casting Al-Si alloy, it can be solved by solid solution and aging treatment to improve its properties. The conventional heat treatment method has disadvantages of long treatment time and high energy consumption [2-4]. So far, many domestic and foreign scholars have studied the impact of different parameters on the casting process of ZL114A alloy, including mechanical properties, corrosion resistance and welding performance [5-7]. Xu et al. [8] investigated parts of the intragranular pre- cipitates dissolved in the matrix during the electric pulse, and the electric pulse treated sample exhibited discontinuous dissolution of the grain-boundary precipitates (GBP). After re-aging, the mechanical properties of the re-aged (RA) sample are nearly the same as those of T6 temper, and the grown discontinuous GBP were obtained. Zheng et al. [9] studied the effect of electropulse on solid solution treatment of 6061 aluminum alloy. Their results indicated that the solid-solution treatment of 6061 aluminum alloys by using electropulse tremendously improved the dissolution rate compared with the conventional solution treatment. The effect of electropulse increased the degree of supersaturation of solute elements that led to the formation of more precipitates in the aging process. Gao et al. [10] have studied the effect of the electric current pulse on tensile strength and elongation of casting ZA27 alloy, indicating that the electric current pulse restrained the growth of the dendrite in the alloy and enhanced the tensile strength and the elongation. However, the rapid aging treatment of ZL114A alloy

*Corresponding author: e-mail address: hlgclxy06318@163.com 
Table 1. The chemical composition of ZL114A alloy in mass fractions (wt.\%)

\begin{tabular}{ccccl}
\hline $\mathrm{Si}$ & $\mathrm{Mg}$ & $\mathrm{Ti}$ & $\mathrm{Be}$ & $\mathrm{Al}$ \\
\hline 6.95 & 0.55 & 0.12 & 0.06 & Bal. \\
\hline
\end{tabular}

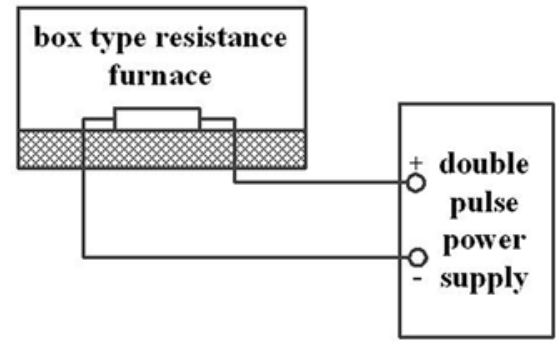

Fig. 1. Schematic diagram of electric pulse aging process.

has not been studied systematically.

In this study, ZL114A alloy was treated by solid solution at a constant temperature for a specific time. Then electric pulse was applied during aging treatment that changed aging time with a constant pulse current, pulse frequency, and duty cycle. The optimum electric pulse aging time was selected by changes of conductivity, hardness, and tensile properties of the alloy before and after aging and organization analysis of ZL114A alloy, which determined that the aging treatment time of ZL114A alloy was significantly reduced by using electric pulse. The study is of great significance to the future industrial production.

\section{Experimental}

The experimental materials were metal mold casting ZL114A alloy rods with the diameter of $20 \mathrm{~mm}$, and their chemical compositions are shown in Table 1. ZL114A alloy bars were treated by solution treatment in a box-type resistance furnace preservation $12 \mathrm{~h}$ at $535^{\circ} \mathrm{C}$ (according to GJB $1695-1993$ of China). Then the alloy bars were removed rapidly from the furnace and carried out by quenching in water at $60^{\circ} \mathrm{C}$. One group of three ZL114A alloy bars were treated by conventional aging treatment in a box-type resistance furnace at $160^{\circ} \mathrm{C}$ for $8 \mathrm{~h}$. Then the basic principles of electric pulse aging treatment by using the SOYI-5020DM dual pulse power supply are shown in Fig. 1. Each group of three ZL114A alloy bars was connected in series with copper wire. The binding of copper wire should be as close as possible to the two free ends of the test bars so that the length of the contact cur-

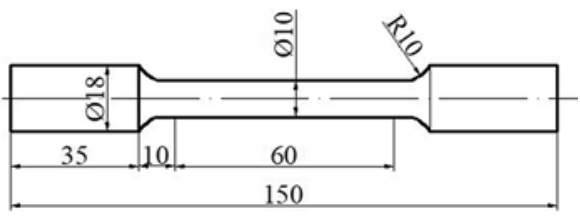

Fig. 2. Standard tensile test bar of the ZL114A alloy.

rent can be increased as much as possible. The two ends of the copper wire were connected to the output end of double pulse power supply. When the box type resistance furnace temperature was $160^{\circ} \mathrm{C}$, the alloy bars were put into the furnace for aging treatment. Dual pulse power supply was turned on, and the corresponding parameters were set up. The ZL114A alloy bars were holding corresponding time and removed rapidly from furnace to air cooling.

The specific experimental parameters were determined: pulse current of $8 \mathrm{~A}$, pulse frequency of 700 $\mathrm{Hz}$, the duty cycle of \pm 0.5 , and the aging time of 2 , $3,4,5,6$, and $7 \mathrm{~h}$. The conventional heat treatment was used as control group. From the variation of electrical conductivity, hardness and tensile properties of the alloy before and after aging, the optimal parameters of the electric pulse aging process were selected. Electrical conductivities were tested by QJ57p type DC resistance bridge. The tensile mechanical properties were tested by the CSS-44300 electronic universal testing machine, and standard tensile bars were prepared according to the GB/T228.1-2010 of China, as shown in Fig. 2. The microstructures were observed by an optical microscope (GX71, OLYMPUS, Tokyo, Japan). The transmission electron microscopy (JEM-2100 , JEOL, Tokyo, Japan) was used to analyze the microstructure of ZL114A alloy with as-cast alloy, conventional heat treatment alloy and electric pulse aging after solid solution alloy.

\section{Results and discussion}

\subsection{The microstructure of as-cast and conventional heat treatment ZL114A alloy}

The as-cast ZL114A alloy is mainly composed of $\alpha$-Al matrix and eutectics. As is well-known, silicon nucleates at grain boundaries in the process of solidification of ZL114A alloy and exists in the eutectic Si. The microstructure of as-cast ZL114A alloy is shown in Fig. 3a. The morphology of eutectics in ZL114A alloy is mainly long and thin strip, and a little short and thick strip or broken lump. The long and thin strip eutectics distribute disorderly along grain boundaries in the $\alpha$-Al matrix due to segregation. Tearing effects play a negative role in the matrix because of its sharp 

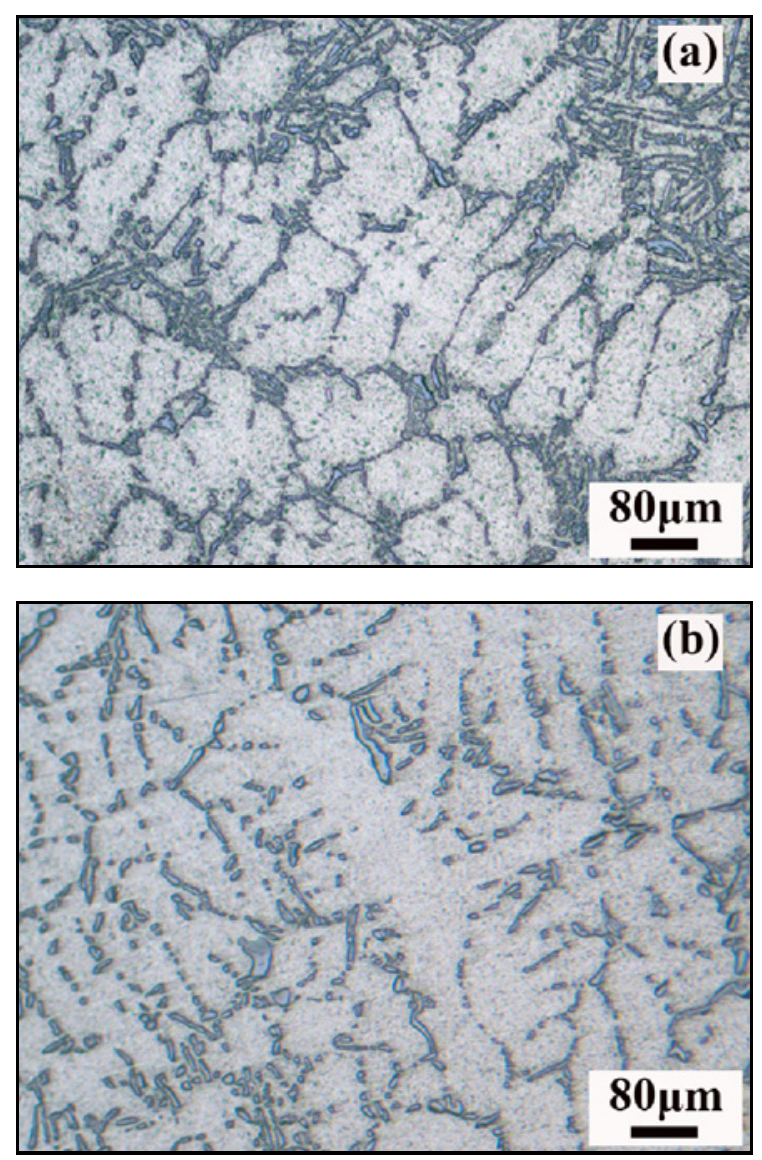

Fig. 3. The microstructure of ZL114A alloy: (a) as-cast and (b) conventional heat treatment.

end, leading to poor properties of as-cast ZL114A alloy $[11]$.

Figure 3b shows the microstructure of ZL114A alloy treated by conventional heat treatment. It can be seen that phase morphology of the alloy changed obviously. Compared with the as-cast microstructure in Fig. 3a, the number of long and thin strip eutectic Si obviously reduces. Short strips or granular eutectics distribute uniformly in the $\alpha$-Al matrix, improving the mechanical properties of the alloy, which alleviates the tearing effects in the $\alpha$-Al matrix [12].

Figures $4 \mathrm{a}, \mathrm{b}$ show the fracture morphology of ascast and conventional heat treatment ZL114A alloy. The as-cast microstructure of ZL114A alloy is mainly composed of $\alpha$-Al matrix and eutectics. Microcracks are easily formed in silicon phase when the alloy is subjected to external stress because the silicon element belongs to brittle phase. With the increase of the external stress, the microcrack gradually grows outwards until the alloy breaks. The fracture morphology of conventional heat treatment ZL114A alloy compares to as-cast ZL114A alloy, quantities of dimples are increasing, and there are tiny bright white inclusions or precipitated particles at the bottom of the dimples. It reduces the stress concentration at the grain bound-
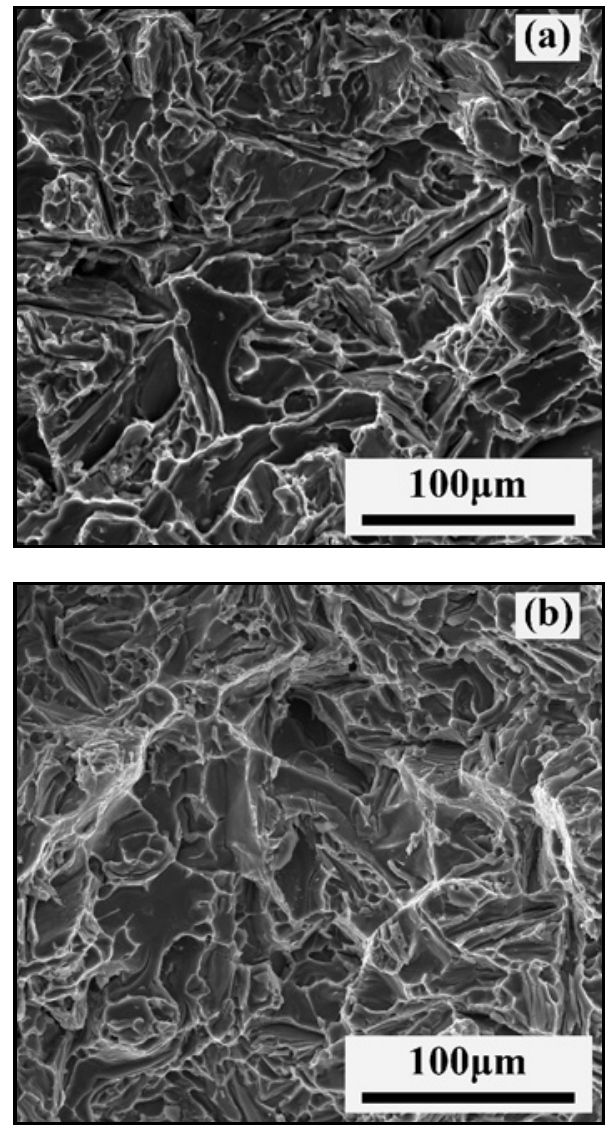

Fig. 4. Fracture morphology of ZL114A alloy: (a) as-cast and (b) conventional heat treatment.

aries of eutectics and $\alpha$-Al matrix and prevents the generation and extension of microcracks. The mechanical properties of ZL114A alloy after heat treatment are significantly improving.

\subsection{Effect of electric pulse aging time on microstructure of ZL114A alloy}

Figure 5 shows the microstructure of the ZL114A alloy samples with different electric pulse aging time. The ZL114A alloy is mainly composed of an $\alpha-\mathrm{Al}$ matrix, eutectics and a small amount of $\beta$-phase $\left(\mathrm{Mg}_{2} \mathrm{Si}\right)$ after heat treatment. There are a large number of elongated eutectics in the $\alpha$-Al matrix as shows the microstructure of ZL114A alloy treated electric pulse aging $2 \mathrm{~h}$ in Fig. 5a. Compared with the microstructure of the as-cast ZL114A alloy, the coarse and elongated eutectics have a certain refinement, and the precipitates in grain boundaries become obtuse. With the increasing of electric pulse aging time, the size of eutectics is refined gradually and uniformly distributed in the $\alpha$ - $\mathrm{Al}$ matrix. Figure 5d shows the microstructure of ZL114A alloy treated by electric pulse aging $5 \mathrm{~h}$. It can be apparently seen that most refined eutectics are uniformly distributed in the $\alpha$-Al matrix. How- 

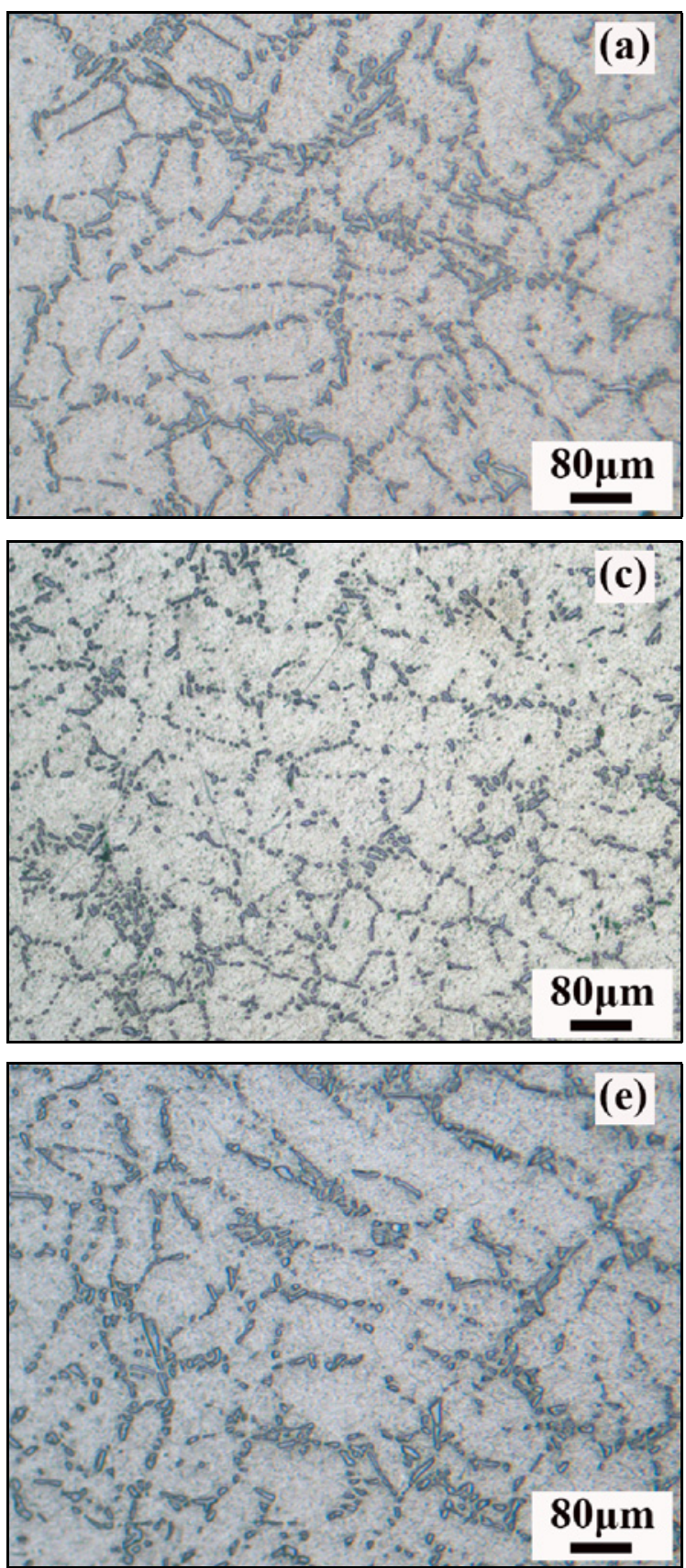
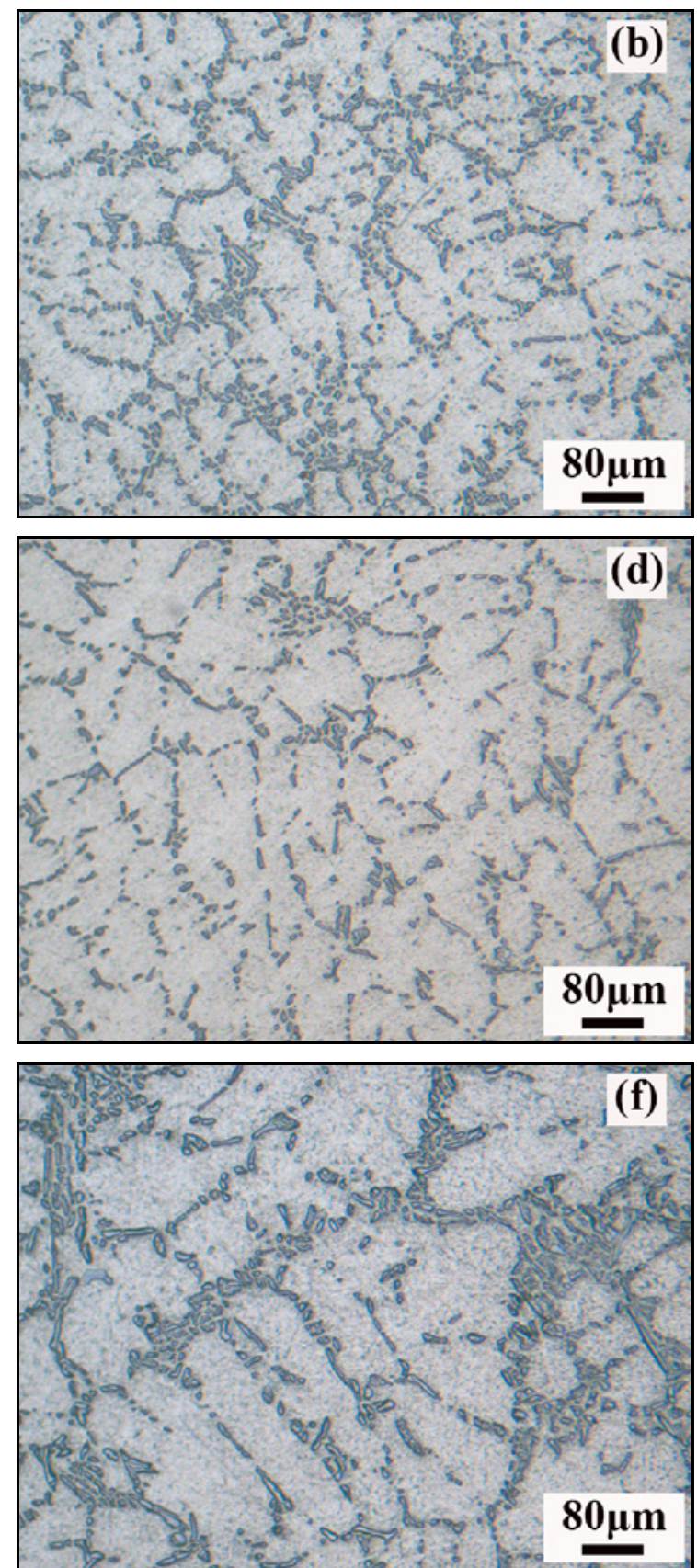

Fig. 5. The microstructure of the ZL114A alloy with different electric pulse aging time: (a) $2 \mathrm{~h}$, (b) $3 \mathrm{~h}$, (c) $4 \mathrm{~h}$, (d) $5 \mathrm{~h}$, (e) $6 \mathrm{~h}$, and (f) $7 \mathrm{~h}$.

ever, the segregation of eutectics becomes larger in the $\alpha$-Al matrix with aging time prolonging to $6 \mathrm{~h}$ and $7 \mathrm{~h}$. The eutectics are first refined and then become coarse with the increasing of aging time. Under certain conditions, when the ZL114A alloy electric pulse aging time is $5 \mathrm{~h}$, the microstructure of the alloy is refined, and the eutectics distribute uniformly.

\subsection{Analysis of TEM microstructure at different aging time}

The Al-Si-Mg alloy is mainly composed of $\alpha-\mathrm{Al}$ matrix and eutectics $(\alpha-\mathrm{Al}+\mathrm{Si})$. A small fraction of $\mathrm{Si}$ forms $\beta$-phase $\left(\mathrm{Mg}_{2} \mathrm{Si}\right)$. The $\mathrm{Si}$ element can control the number of $\mathrm{Mg}$-Si cluster and GP zone in precipitation sequence of alloy aging. Owing to the subtle content of $\mathrm{Mg}$ in ZL114A alloy, the precipitates of $\beta$-phase $\left(\mathrm{Mg}_{2} \mathrm{Si}\right)$ are less after aging treatment. Figure 6 shows the microstructure of ZL114A alloy with different aging time by Transmission Electron Microscope (TEM). The morphology and distribution of precipitates treated by electric pulse aging $3 \mathrm{~h}$ (Fig. 6a) shows lots of dots ( $\mathrm{Si}$ ) uniformly distributed in the matrix with a diameter of less than 

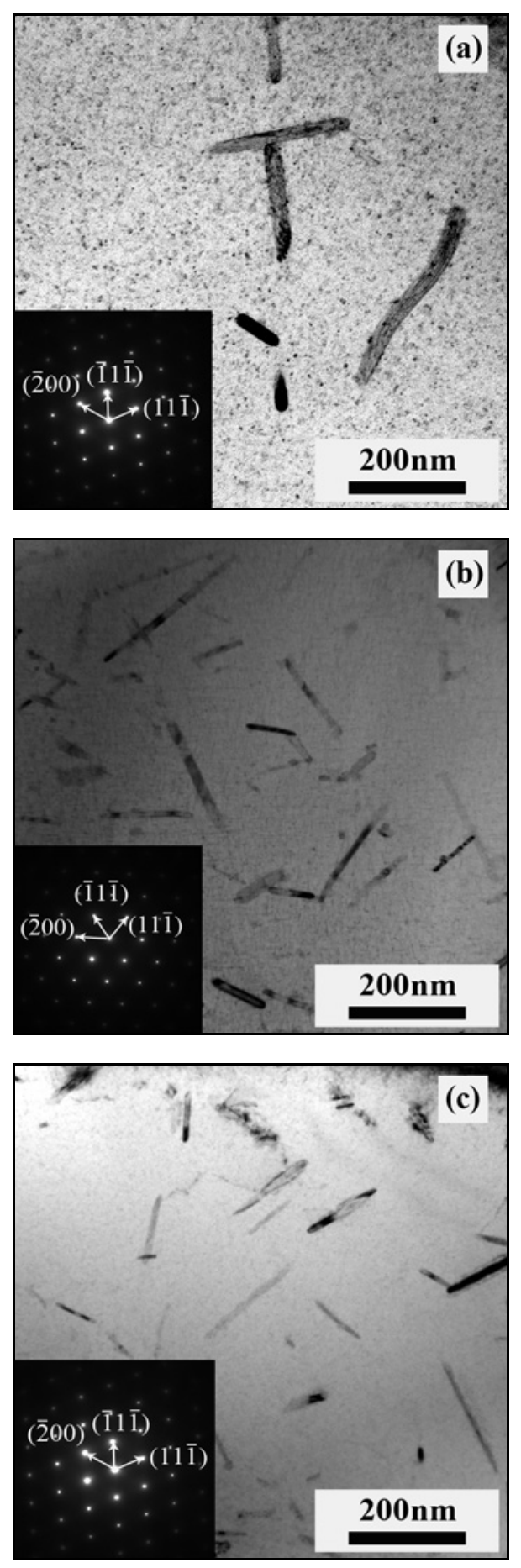

Fig. 6. TEM microstructure morphologies of ZL114A alloy and associated SAED of $[110]_{\mathrm{Al}}$ at the different aging time: (a) electric pulse aging $3 \mathrm{~h}$, (b) electric pulse aging $7 \mathrm{~h}$, and (c) conventional heat treatment.

$9 \mathrm{~nm}$ and a few different lengths of rod precipitates ( $\beta$-phase) about $46-232 \mathrm{~nm}$ long, $14-32 \mathrm{~nm}$ wide. Figure $6 \mathrm{~b}$ shows the morphology of precipitates and selective electron diffraction (SAED) at electric pulse aging $7 \mathrm{~h}$. The precipitated phase of Si decreases obviously,

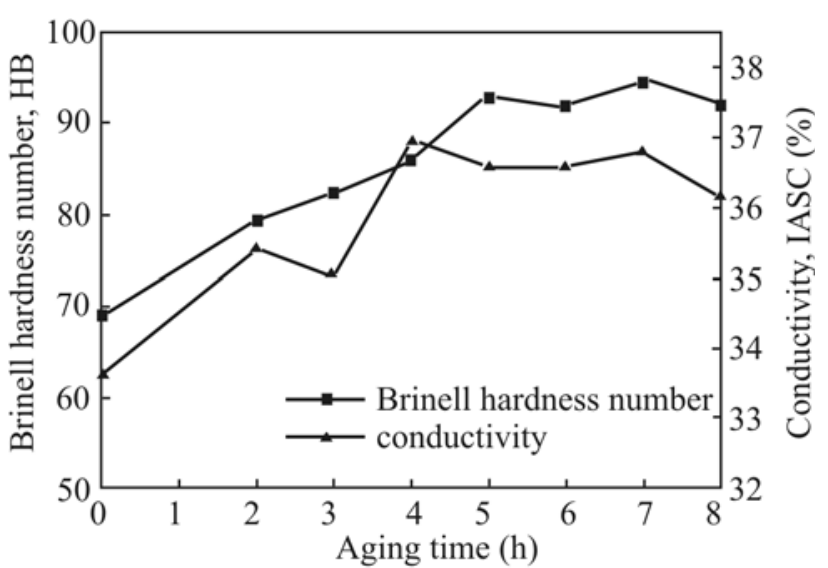

Fig. 7. The curves of hardness and conductivity of the ZL114A alloy with different aging time.

and the rod precipitated phase of $\mathrm{Mg}_{2} \mathrm{Si}$ increases gradually. The length and width of precipitation phase $\left(\mathrm{Mg}_{2} \mathrm{Si}\right)$ is about $50-150 \mathrm{~nm}$ and $15-25 \mathrm{~nm}$. The morphology of precipitates and selective electron diffraction (SAED) at conventional aging $8 \mathrm{~h}$ are shown in Fig. 6c. Compared with electric pulse aging $3 \mathrm{~h}$, the precipitated phase of $\mathrm{Si}$ decreases, whereas the rod precipitated phase of $\mathrm{Mg}_{2} \mathrm{Si}$ increases. The rod precipitated phase of $\mathrm{Mg}_{2} \mathrm{Si}$ is about the same as electric pulse aging $7 \mathrm{~h}$. The rate of precipitation of rod precipitates $\left(\mathrm{Mg}_{2} \mathrm{Si}\right)$ can be accelerated by applied electric pulses in alloy aging. With the prolonging of aging time, the number of rod precipitates $\left(\mathrm{Mg}_{2} \mathrm{Si}\right)$ increases that made the strength of ZL114A alloy increase. The small rod precipitated phases of ZL114A alloy increase compared electric pulse aging $7 \mathrm{~h}$ with $3 \mathrm{~h}$. For this phenomenon, Marioara et al. [13] studied that the $\mathrm{Mg}$ and $\mathrm{Si}$ elements in the supersaturated solid solution were segregated when the aging time was short, and the $\alpha$-Al matrix was constantly replaced by $\mathrm{Mg}$ and Si elements. At this time, the GP zone forms that is completely coherent with the matrix. The number of precipitated phases increases and GP zone gradually transforms to $\beta^{\prime \prime}\left(\beta^{\prime}\right)$-phase. It effectively improves the strength of ZL114A alloy. The aging time has a direct influence on the size of precipitates in the aging treatment of ZL114A alloy, so the properties of the alloy are closely related to aging time.

\subsection{Effect of electric pulse aging time on properties of ZL114A alloy}

Figure 7 shows that the hardness and electrical conductivity of ZL114A alloy vary with aging time. They are as-cast and conventional heat treatment ZL114A alloy when aging time is $0 \mathrm{~h}$ and $8 \mathrm{~h}$. The hardness and electrical conductivity of as-cast and after conventional heat treatment ZL114A alloy are 69 


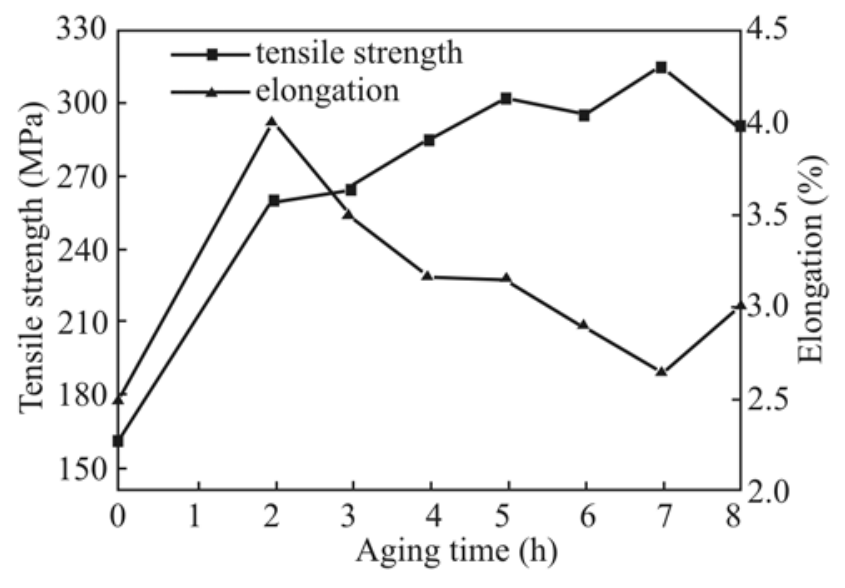

Fig. 8. The curves of tensile strength and elongation of the ZL114A alloy with different aging time.

HB, $33.6 \%$ IACS, $92 \mathrm{HB}, 36.1 \%$ IACS, respectively. The hardness of the alloy gradually increases with the prolonging of electric pulse aging time. The hardness is almost flat ZL114A alloy treated by electric pulse aging $5-7 \mathrm{~h}$ and conventional heat treatment $(92 \mathrm{HB})$. The electrical conductivity of the alloy is increasing and then has gradual declining tendency. The electrical conductivity of ZL114A alloy with 4-7 h electric pulse aging treatment is significantly higher than that of the as-cast alloy. Besides, the electrical conductivity of the alloy is also a little more than conventional heat treatment.

The electrical conductivity of ZL114A alloy has a direct relationship with the precipitated phase velocity during the aging treatment. With the prolonging of electric pulse aging time and precipitates in the alloy, the lattice distortion and effect of electron scattering show the downtrend. The relative electron scattering of the precipitate is less than that of the lattice distortion in the $\alpha$-Al matrix, which increases the conductivity of ZL114A alloy obviously. However, saturation of solid solution decreases with the continuous precipitation of the precipitated phase in the alloy, leading to the decreasing precipitation rate of precipitated phase. The electrical conductivity of alloy tends to be stable with the precipitated phase equilibrium. Generally, the electrical pulse and short aging time have a significant effect on improving hardness and conductivity of ZL114A alloy.

Figure 8 shows the tensile strength and elongation curve of ZL114A alloy vary with aging time. They are as-cast and conventional heat treatment ZL114A alloy when aging time is $0 \mathrm{~h}$ and $8 \mathrm{~h}$. Under the same solution treatment, the ZL114A alloy is treated by electric pulse aging with pulse current of $8 \mathrm{~A}$, pulse frequency of $700 \mathrm{~Hz}$, the duty cycle of 0.5 and aging heat preservation of $2,3,4,5,6$, and $7 \mathrm{~h}$. With increasing of aging time, the tensile strength of ZL114A alloy ex- hibits an " $\mathrm{M}$ " type increasing. The tensile strength of ZL114A alloy after heat treatment increases significantly compared with the as-cast alloy. When the aging time is less than $2 \mathrm{~h}$, the tensile strength of the alloy is poor due to the short electric pulse aging time and the small number of metastable $\beta^{\prime \prime}\left(\beta^{\prime}\right)$-phases. The alloy has higher tensile strength with longer aging time. When electric pulse aging time is 5,6 , and $7 \mathrm{~h}$, the tensile strength of the alloy is 302,295 , and $315 \mathrm{MPa}$, respectively. That is all tensile strength values are higher than after $8 \mathrm{~h}$ conventional aging treatment $(290 \mathrm{MPa})$. With the prolonging of aging time, the elongation of ZL114A alloy decreases rapidly and slowly after aging $2-4 \mathrm{~h}$ and $5-7 \mathrm{~h}$. The metastable phase in the alloy gradually transforms to the stable brittle phase $(\beta)$. When electric pulse aging time is $5 \mathrm{~h}$, the tensile strength and elongation of ZL114A alloy are better than those of conventional heat treatment.

The complex precipitation sequence for Al-Si alloy aging process is generally considered to be as follows: supersaturated solid solution phase of $\alpha$-Al $\rightarrow$ GP zone $\rightarrow \beta^{\prime \prime}\left(\beta^{\prime}\right)$-phase $\rightarrow \beta$-phase [14-17]. The alloy is treated by electric pulse aging after solution and quenching treatment. Solid solution of Si and Mg elements are recombining in the $\alpha$-Al matrix, and solute atoms show segregation at this time. GP zone maintains a completely coherent relationship with the $\alpha-\mathrm{Al}$ matrix. With the increasing of lattice distortion, internal dislocation movement is inhibited. The mechanical properties of ZL114A alloy increase significantly while the conductivity decreases [18-21]. GP zone develops and gradually grows up with the aging time prolonging of ZL114A alloy. Then GP zone transforms into $\beta^{\prime \prime}\left(\beta^{\prime}\right)$-phase, which maintains a semi-coherent relationship with the $\alpha$-Al matrix. The sizes of eutectics and $\beta^{\prime \prime}\left(\beta^{\prime}\right)$-phase are small and uniformly distributed that the ZL114A alloy owns excellent properties now. With the increasing of aging time, metastable phase $\left(\beta^{\prime \prime}\left(\beta^{\prime}\right)\right.$-phase) gradually transforms into stable phase ( $\beta$-phase). Fine precipitates distribute inside the matrix while coarse precipitates distribute in the grain boundaries. With the reducing of lattice distortion, the strength and hardness of ZL114A alloy decrease, but plasticity and toughness increase. In conclusion, the eutectics aggregate and coarsen treated by electric pulse aging $7 \mathrm{~h}$. The eutectics are refined and distribute uniformly, and ZL114A alloy owns excellent properties treated by electric pulse aging $5 \mathrm{~h}$.

\section{Conclusions}

The ZL114A alloy owns finer and uniform microstructure and excellent properties, under the same solution treatment, is treated by electric pulse aging with the aging temperature of $160^{\circ} \mathrm{C}$, the duty cycle of 0.5 , pulse current of $8 \mathrm{~A}$, pulse frequency of $700 \mathrm{~Hz}$ 
and aging treatment time of $5 \mathrm{~h}$. Compared with conventional heat treatment, it shortens $3 \mathrm{~h}$ aging time and saves energy.

The internal atoms of ZL114A alloy strike in two directions during the aging treatment because of the combination of electric and temperature field. The contents of silicon and magnesium are constant in ZL114A alloy, so the number of precipitates is continuously precipitating from the supersaturated solid solution. The activation energy of diffusion reduces by applying a small pulse current in ZL114A alloy that increases the atomic diffusion rate, nucleation rate of eutectic and precipitated phase $\left(\mathrm{Mg}_{2} \mathrm{Si}\right)$, which is beneficial to the vacancy movement. It leads to obtaining more uniform and finer precipitates.

\section{Acknowledgements}

The authors acknowledge the financial support from the Research and Development Project of Application Technology in Harbin, Heilongjiang Province of China (2017RAYXJ017).

\section{References}

[1] Jiang, W. L., Wu, G. H., Yang, W. P., Zhao, Y. G., Liu, S. S.: China J Nonferrous Met, 20, 2010, p. 2124. doi:10.1016/S1003-6326(09)60428-3

[2] González-Rivera, C., Campillo, B., Castro, M., Herrera, M., Juárez-Islas, J.: Mater. Sci. Eng. A, 279, 2000, p. 149. doi:10.1016/s0921-5093(99)00625-5

[3] Furui, M., Kitamura, T., Ishikawa, T., Ikeno1, S., Saikawa, S., Sakai, N.: Mater. Trans., 52, 2011, p. 1163. doi: $10.2320 /$ matertrans.mb201010

[4] Han, N. H., Zhang, X. M., Liu, S. D., He, D. G., Zhang, R.: J. Alloys Compd, 509, 2011, p. 4138. doi:10.1016/j.jallcom.2011.01.005

[5] Timelli, G., Lohne, O., Arnberg, L., Laukli, H. I.: Mater. Trans., 39, 2008, p. 1747. doi:10.1007/s11661-008-9527-0
[6] Akhil, K. T., Arul, S., Sellamuthu, R.: Procedia Eng., 97, 2014, p. 1676. doi:10.1016/j.proeng.2014.12.318

[7] Elagin, V. I., Zakharov, V. V.: Met. Sci. Heat Treat., 36, 1994, p. 597. doi:10.1007/bf01402791

[8] Xu, X. F., Zhao, Y. G., Ma, B. D., Zhang, M.: Mater. Charact., 105, 2015, p. 90. doi:10.1016/i.matchar.2015.05.007

[9] Zheng, Y. S., Tang, G. Y., Kuang, J., Zheng, X. P.: J. Alloys Compd., 615, 2014, p. 849. doi:10.1016/j.jallcom.2014.07.062

[10] Gao, M., He, G. H., Yang, F., Guo, J. D., Yuan, Z. X., Zhou, B. L.: Mater. Sci. Eng. A, 337, 2002, p. 110. doi:10.1016/s0921-5093(02)00026-6

[11] Gupta, A. K., Lloyd, D. J., Court, S. A.: Mater. Sci. Eng. A, 316, 2001, p. 11. doi:10.1016/s0921-5093(01)01247-3

[12] Naumova, E. A., Belov, N. A., Bazlova, T. A.: Met. Sci. Heat Treat., 57, 2015, p. 1. doi:10.1007/s11041-015-9874-6

[13] Marioara, C. D., Andersen, S. J., Jansen, J., Zandbergen, H. W.: Acta Mater., 51, 2003, p. 789. doi:10.1016/s1359-6454(02)00470-6

[14] Akyüz, B.: Kovove Mater., 55, 2017, p. 237. doi:10.4149/km_2017_4_237

[15] Tian, G. G., Wang, H. G.: Adv. Eng. Plast. Appl., 1993, p. 303. doi:10.1016/B978-0-444-89991-0.50042-1

[16] Myhr, O. R., Grong, Ø., Fjær, H. G., Marioara, C. D.: Acta Mater., 52, 2004, p. 4997. doi:10.1016/j.actamat.2004.07.002

[17] Starink, M. J., Gao, N., Davin, L., Yan, J., Cerezo, A.: Philos. Mag., 85, 2005, p. 1395. doi:10.1080/14786430412331333374

[18] Murayama, M., Hono, K.: Acta Mater., 47, 1999, p. 1537. doi:10.1016/s1359-6454(99)00033-6

[19] Murayama, M., Hono, K., Saga, M., Kikuchi, M.: Mater. Sci. Eng. A, 250, 1998, p. 127. doi:10.1016/s0921-5093(98)00548-6

[20] Toshiro, K.: Mater. Sci. Forum, 426-432, 2003, p. 67. doi:10.4028/www.scientific.net/MSF.426-432.67

[21] Hono, K., Murayama, M.: Mater. Japan, 38, 1999, p. 563. doi: $10.2320 /$ materia. 38.563 